\title{
FUNDACIÓN TRANSFORMAR: UNA OPCIÓN QUE GENERA CALIDAD DE VIDA
}

\author{
Nayibe Pedraza Céspedes \\ Comunicadora Social-Periodista \\ Esp. En Gerencia de la Comunicación Organización \\ Universidad Ponticia Bolivariana
}

Lograr que cada día vivido sea una experiencia llena de mística y voluntad de ser mejor persona, más fraterna, justo y solidario, ha sido el deseo que la Fundación para el desarrollo integral de la comunidad, Transformar. Este proyecto ético se ha desarrollado con las comunidades vulnerables de Bucaramanga y su Área Metropolitana.

El contexto social y político en Colombia caracterizado por la desigualdad en la distribución de la riqueza, tanto económica como cultural, revela altos índices de pobreza. Aunado a esta situación el maltrato intrafamiliar, recrudece el conicto y hasta sectoriza por clases sociales y culturales a la población del territorio. Es este un país que no considera a la persona como ser integral, que piensa, sueña, es, quiere y puede.

Este contexto unido a la experiencia vivida en los años setenta del Grupo Juvenil de la Parroquia de Lagos en Floridablanca (COJULA), reunió a estos jóvenes, ya profesionales y desarrollando sus expectativas familiares y personales, con la gran inquietud de promover un espacio diferente, auténtico e innovador que se distinguiera por promover la calidad de vida de las personas y la comunidades más vulnerables, porque allí, en medio de la pobreza, inician los brotes de desarrollo "si se enseña al hombre con hambre a pescar".

El sacerdote católico Hernando Pinilla Rey, quien era el párroco en aquella época, siguió acompañando a los excojuleños en la iniciativa que más tarde se llamaría Fundación Transformar, bajo el principio de la Antropología del pobre ante quien "hay que evitar todo comple- en expresiones como "yo le doy" y "yo voy a salvar al pobre", comunes a las fundaciones y propuestas gubernamentales que han existido en Colombia y que acunan la cultura del paternalismo y asistencialismo.

El 30 de diciembre de 1988 la idea de responder con alternativas transformadoras a las necesidades y problemáticas de las comunidades vulnerables, entendidas como las situaciones de desplazamiento, pobreza, victimización y destechados, adquiere personería jurídica y registro legal para trabajar despertando en otros profesionales, a través de las universidades, las empresas y los gremios de la ciudad, el factor "T" o factor Transformar, que consiste en descubrir el sentido social que impulsa a la persona a promover la dignicación del ser humano empezó a ser una realidad tangible.

Al proceso que inició en Ciudad Norte se unieron estudiantes universitarios en calidad de practicantes, profesionales voluntarios y también excojuleños atraídos por una nueva experiencia de transformación, amigos y empresas que se han ido solidarizando con los nes y programas de la Fundación Transformar y quienes, a través de su apoyo nanciero y en especie, logran un proceso de cambio y apoyan el fortalecimiento de la organización.

Con el objetivo de darle pertinencia social y política al papel de la Fundación Transformar en las personas, tanto de quienes ofrecen su apoyo solidario como de quienes se benecian, la organización motiva en el proyecto de vida de sus miembros, el compromiso de aportar a la construcción de aprendizajes exitosos, es de- 
cir, experiencias de desarrollo humano integral, familiar, y comunitario.

La Fundación Transformar capitalizó la formación humana, pedagógica, teológica, económica y empresarial de sus fundadores César Augusto Roa y Álvaro González Rodríguez, para convertirla en una práctica de educación no formal, que entra en la modalidad de educación popular y busca que las personas se hagan sujetos de sí mismos y de su propio desarrollo a través de la dinámica constante de hacernos sus hermanos, de escucharlos y entenderlos para ayudar a transformar su mundo desde dentro.

Los modelos de investigación de la realidad social tradicionales destacan la labor de un grupo de especialistas (sujeto de investigación), que abordan una realidad y comunidad (objeto de investigación), para comprobar una hipótesis o describir una situación. Con el ánimo de que la comunidad no sea sólo ese "objeto de investigación" y de lograr un verdadero acercamiento entre quienes ofrecen su ayuda y quienes la reciben en un proceso recíproco de participación, la Fundación Transformar ha moldeado su trabajo a partir de la permanencia dentro de la comunidad, la investigación, caracterización y formulación de planes de formación aterrizados, acompañados de la transformación mental para la construcción de alternativas productivas y de ingresos formales, así como la educación de líderes juveniles.

César Augusto Roa, conesa que él mismo fue parte de un proceso de animación juvenil que le fue entregando la posibilidad de formarse en el liderazgo de estos grupos. "Sumado a esa experiencia de COJULA y con mi formación universitaria, ciertas circunstancias personales y sociales hicieron que me convirtiera en lo que soy, un sujeto de formación para ayudar a promover a otros, en la educación para el trabajo y el desarrollo humano" asegura este miembro fundador, docente en la Universidad Industrial de Santander.
Por su parte, Álvaro González Rodríguez, maniesta que su experiencia personal de nacer en el seno de una familia numerosa y humilde, pero también muy creyente, le inculcó la disciplina y el sentido social que lo llevaron también a liderar a COJULA en su momento, y a trabajar desde pequeño en múltiples labores como la mensajería, la preparación y venta ambulante de alimentos, entre otros, para darse el estudio y ayudar a la familia.

"Desde que tuve mi primera microempresa a los 16 años compartía mi negocio con las personas que estaban a mi alrededor, siempre tenía disponible qué dar, qué ayudar y eso ha sido una constante a lo largo de mi vida. En la medida que yo soy generoso la vida misma lo retribuye", afirma Álvaro González, miembro fundador y gerente de INSURCOL LTDA., una empresa santandereana pujante y la primera en Latinoamérica certificada por la norma SGE 21 de Gestión Ética y Socialmente Responsable.

El binomio pedagogía y emprendimiento articulado a la realidad interna de la comunidad, ha generado una experiencia de formación humana integral que sigue siendo opción de calidad de vida en los sectores donde ha trabajado la Fundación Transformar, con su equipo humano y la red de amigos, empresas solidarias y alianzas interinstitucionales.

La primera experiencia del modelo de formación humana integral que promueve la Fundación Transformar se llevó a cabo en Ciudad Norte. En el sector de Regaderos Norte se estableció una casa desde donde el equipo humano y voluntario proyectaba los programas y el trabajo de campo, bajo la dirección de César Augusto Roa y el apoyo de Adriana Villamizar, Iris Correa, Yolanda Pinto, José Alfredo Pedraza, entre muchos otros, de empresas como INSURCOL, y de gestión de proyectos de cooperación de la Conferencia de Obispos Americanos, el Programa por la Paz, la Fundación Restrepo Barco, el Programa "Compartir", FUNDESAN 
y la Personería de Bucaramanga permitieron consolidar 73 alternativas productivas, $153 \mathrm{em}$ pleos directos, 137 empleos indirectos, 500 beneciarios directos integrantes de 98 familias y programas de comercialización de 30 Unidades Productivas.

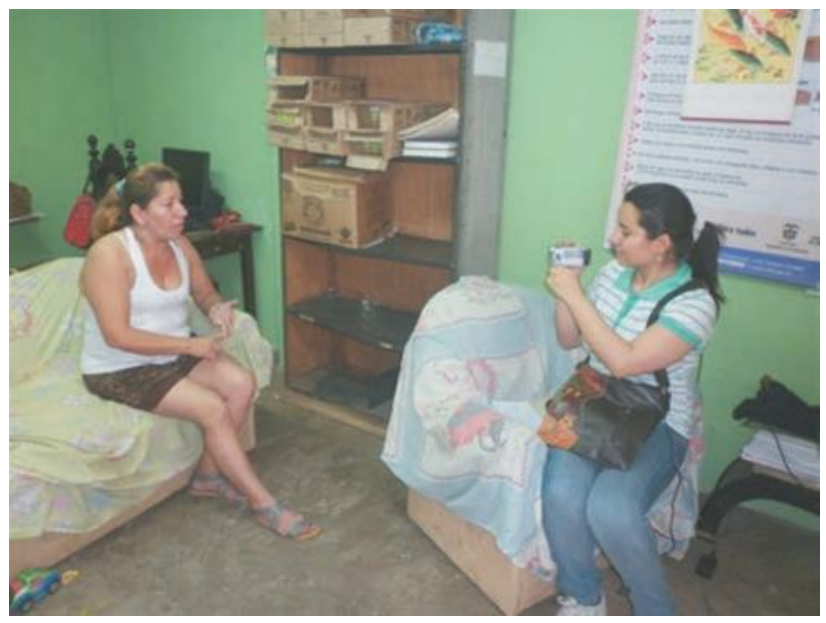

Ana Sandra Martínez, entrevistada en la sala de su casa

Los testimonios en Ciudad Norte son la primera carta de presentación de Transformar y la garantía de que la experiencia cosecha frutos más allá de los esperados. Ana Sandra Martínez y su familia es uno de esos testimonios que sobrepasan la pobreza y la convierten en una condición de desarrollo: " Cuando ingresé al programa de la Fundación Transformar quería que mis hijos estudiaran, salieran adelante(...) gracias a Transformar tengo una familia unida, todos mis hijos han estudiado y nosotros no tenemos muchas riquezas pero si muchos valores, y aunque hemos tenido problemas, siempre hemos salido adelante, mi familia aprendió a trabajar en marroquinería y todos hacemos bolsos de diferentes estilos y ya comercializamos en Bucaramanga", asegura Ana Sandra con la certeza de saber que sus hijos, como muchos otros niños de la época de los 90 en Ciudad Norte, pudieron haber sido consumidores de droga, asaltantes, hombres violentos pero que, gracias a Dios, se les presentó una alternativa distinta.

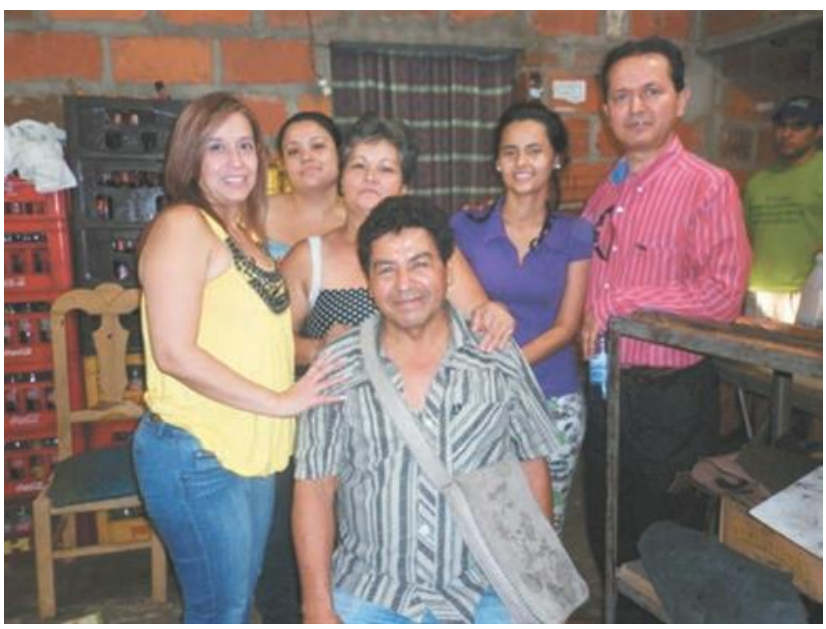

Reimundo Ortiz Vera y su familia, entre Adriana Villamizar (izq) y Álvaro González Rodríguez (der.)

Reimundo Ortíz Vera es un líder de la comunidad en Ciudad Norte, cuando la Fundación Transformar lo conoció era un empleado que sostenía a su familia con sus cortos ingresos y a través del apoyo a los microempresarios que ofrece la Fundación Transformar Reimundo comprendió que podía crear su propio negocio y se dedicó a la zapatería artesanal, sus hijas y su esposa también aprendieron a trabajar y hoy cada uno tiene su propio negocio familiar y una mejor calidad de vida. "Aquí en los noventa había muchas fundaciones y programas del gobierno que entregaban regalos, ropa y comida, pero la fundación Transformar era la única que nos capacitaba y nos ayudó a ser empresarios", arma Reimundo.

Luego de la grata experiencia de vida que se tuvo en Ciudad Norte y por su creciente nivel de desarrollo y la ampliación de programas del gobierno en este sector, la Fundación Transformar tomó la decisión de identicar una nueva comunidad en condición de vulnerabilidad y fue así como continuó con su fortaleza pedagógica y de emprendimiento en el Asentamiento Humano de Guatiguará- Nueva Colombia, comprendido por 5 sectores poblacionales que comprenden el $2,5 \%$ de la población de Piedecuesta y viven en terrenos de invasión y en condiciones precarias. 
Desde el año 2007, con el apoyo de las Hijas de la Caridad de San Vicente de Paúl, la Fundación Transformar identicó en el Asentamiento las problemáticas que hacían posible la intervención de los programas y la creación de nuevos proyectos a partir de su propia realidad.

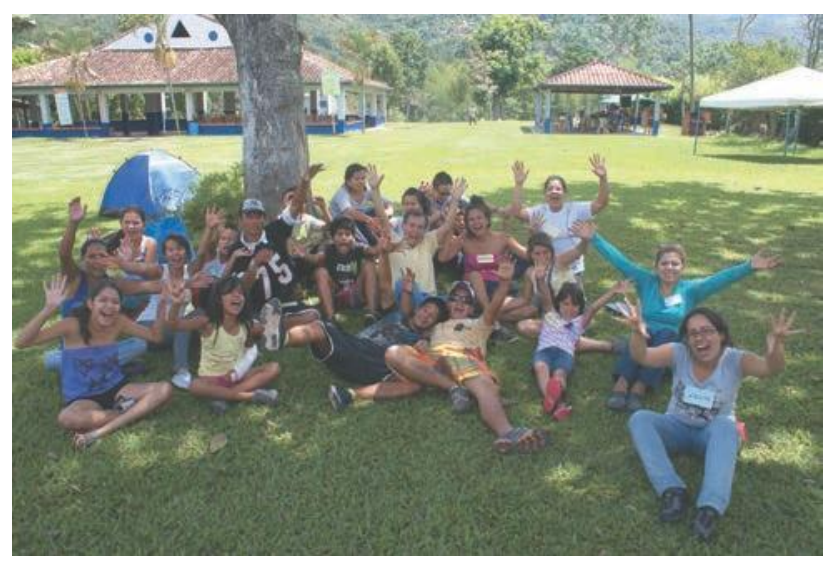

Algunos jóvenes integrantes del Grupo Juvenil "Águilas de Dios formando jóvenes" de Guatiguará - Nueva Colombia.

Contamos con 55 familias que han creado y se encuentran fortaleciendo sus alternativas productivas, 30 jóvenes que son el semillero del grupo juvenil "Águilas de Dios formando jóvenes" como ellos mismos quisieron denominarse, niños y niñas que también han sido apoyados para prevenir la deserción escolar y la desnutrición, así como madres y padres cabeza de hogar que hacen parte de un proceso de educación no formal en emprendimiento y liderazgo.

Además, el trabajo interinstitucional ha tomado su propio vuelo a través de "la Red, educando construimos futuro", alianza social y comunitaria conformada por las Hijas de la Caridad de San Vicente de Paúl en Piedecuesta, la Iglesia Evangélica Luterana San Juan, Visión Mundial y la Fundación Transformar. Juntos trabajan de la mano con la comunidad en la construcción de un Plan Piloto de Desarrollo de Guatiguará - Nueva Colombia.
"Este proceso surgió a raíz de que hay varias instituciones que trabajaban en el asentamiento, cada uno con su carisma, pero con el objeto común de atenuar las necesidades de formación en lo productivo, laboral y espiritual, entonces decidimos unirnos para trabajar juntos por la comunidad", asegura César Roa, coordinar de la Red describiendo cómo lograron articular las organizaciones para que se apostara a trabajar en alianza y red.

Las condiciones sociales y políticas no han tenido cambios estructurales en Colombia, la superación de la pobreza sigue siendo un objetivo lejano, siempre y cuando se crea que el pobre es solo aquella persona que no tiene acceso a los servicios básicos de salud, educación, empleo y vivienda y por eso se vea como receptora de compasión. Siempre será necesaria la fraternidad, la cooperatividad, la solidaridad, la justicia, la dignicación y la libertad que nos da la transformación mental y cultural de un pueblo que continúa siendo gobernado en general por medios sirvientes y por mentes convenientes.

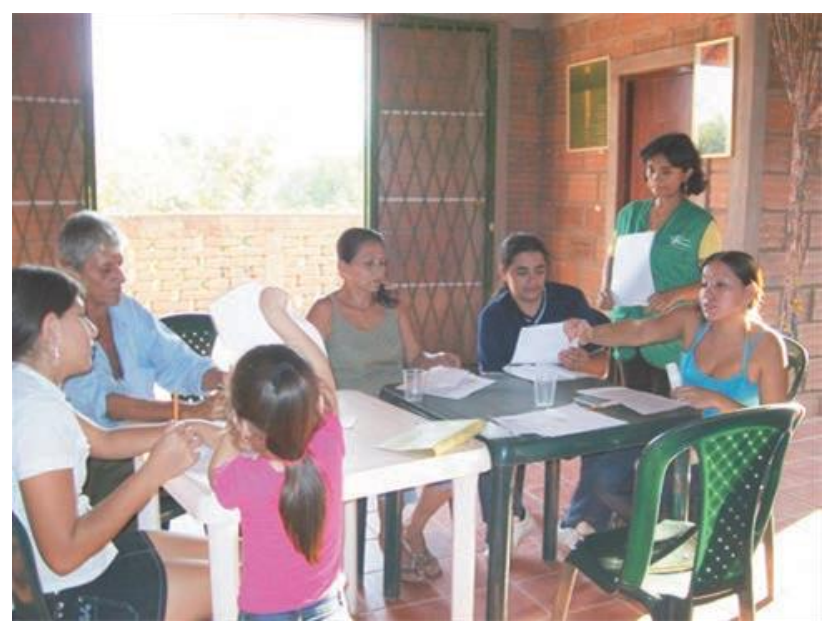

Capacitación de Emprendedores y fortalecimiento de Unidades Productivas en el programa de Alternativas Productivas. 
